\title{
Differential outcomes of residual disease in surgically-resected non-small cell lung cancer and the importance of guideline- concordant adjuvant therapy
}

\author{
Dustin K. Lieu ${ }^{1}$, Li Ding ${ }^{2}$, Elizabeth A. David ${ }^{3}$, Sean C. Wightman ${ }^{3}$, Scott M. Atay ${ }^{3}$, P. Michael McFadden ${ }^{3}$, \\ Anthony W. Kim ${ }^{3}$
}

${ }^{1}$ Keck School of Medicine of the University of Southern California, Los Angeles, CA, USA; ${ }^{2}$ Division of Biostatistics, Keck School of Medicine of the University of Southern California, Los Angeles, CA, USA; ${ }^{3}$ Division of Thoracic Surgery, Keck School of Medicine of the University of Southern California, Los Angeles, CA, USA

Contributions: (I) Conception and design: DK Lieu, L Ding, AW Kim; (II) Administrative support: AW Kim; (III) Provision of study materials or patients: EA David, L Ding, AW Kim; (IV) Collection and assembly of data: DK Lieu, L Ding; (V) Data analysis and interpretation: All authors; (VI) Manuscript writing: All authors; (VII) Final approval of manuscript: All authors.

Correspondence to: Anthony W. Kim, MD. Division of Thoracic Surgery, Keck School of Medicine of the University of Southern California, Los Angeles, CA, USA. Email: anthony.kim@med.usc.edu.

Background: Positive mediastinal lymph nodes, a marker for systemic disease, and positive margins, a marker for local disease, following resection of non-small cell lung cancer (NSCLC) are forms of residual disease. The objective of this study is to compare survival of patients with residual disease and to study the effect of receipt of guideline vs. non-guideline concordant care.

Methods: The National Cancer Database (NCDB) was used to identify patients who underwent treatment naïve surgical resection with clinical stage T1-3N0-1M0 NSCLC between 2006-2016 and had pN2 disease, positive surgical margins, or both. Concordant care was determined based on form of chemotherapy and radiation, dosage, volume, modality, and duration. Kaplan-Meier survival curves and log-rank tests were used to compare five-year survival. Multivariable analysis using Cox proportional hazards modeling identified factors that contributed to worse overall survival.

Results: There were 8,189 patients included: pN2 $(5,416)$, positive margins $(2,386)$, and both (387). Fiveyear survival rates for all patients were $\mathrm{pN} 2(35.8 \%)$, positive margins $(33.9 \%)$, and both $(22.9 \%)(\mathrm{P}<0.0001)$. On multivariable analysis, positive margins were an independent predictor of better survival relative to $\mathrm{pN} 2$ disease ( $\mathrm{HR}=0.729$, CI: 0.676, 0.787, $\mathrm{P}<0.0001)$. Receipt of non-guideline concordant treatment was an independent predictor of worse survival compared to receipt of guideline-concordant treatment $(\mathrm{HR}=1.61$, CI: $1.504,1.725, \mathrm{P}<0.0001)$.

Conclusions: In upfront surgical patients, guideline-concordant treatment in the setting of residual disease is associated with better overall survival compared with non-guideline concordant treatment. Pathologic $\mathrm{N} 2$ disease is associated with a lower survival rate than positive resection margins, possibly reflecting the systemic nature of $\mathrm{pN} 2$ disease.

Keywords: Non-small cell lung cancer (NSCLC); chemotherapy; radiotherapy; margins of excision; surgery

Submitted Jan 18, 2021. Accepted for publication Apr 02, 2021.

doi: $10.21037 /$ jtd-21-110

View this article at: http://dx.doi.org/10.21037/jtd-21-110 


\section{Introduction}

Lung cancer is the second most common cause of cancer in both men and women, and the most common cause of cancer-related mortality nationwide, comprising almost $25 \%$ of all-cancer related deaths (1). Curative intent resection of primary lung tumors is indicated for patients with clinical stage I and II non-small cell lung cancer (NSCLC), as well as for patients with Stage IIIA NSCLC with preoperatively diagnosed discrete N2 involvement (2). Surgery in the setting of primary lung cancer is performed with the goal of curative resection for early stage disease, while surgery for locoregionally advanced disease is usually reserved as one modality of a multimodality treatment paradigm (2). Intraoperatively, however, a surgeon may be faced with two forms of residual disease during resectionpositive residual margins, and occult pathological N2 disease.

Positive surgical margins are subclassified into $\mathrm{R} 1$ resections (microscopic residual tumor) and R2 resections (macroscopic residual tumor). Previous studies have reported an incidence ranging from 4-6\% (3-6). Clinical guidelines for both $\mathrm{R} 1$ and $\mathrm{R} 2$ resections recommend either re-resection of the tumor or adjuvant radiotherapy; some guidelines such as those from the National Comprehensive Cancer Network (NCCN) recommend addition of chemotherapy for more advanced stage malignancies $(2,7,8)$.

Known preoperative N2 disease may be treated with or without surgery; NCCN guidelines for noninvasive T1-3N2M0 disease recommend either definitive concurrent chemoradiation followed by durvalumab or induction chemotherapy with or without radiation followed by surgery if no progression is seen (7). Clinical guidelines recommend neoadjuvant chemotherapy or chemoradiation prior to surgery if an attempt to resect is considered (9). The dilemma arises when occult $\mathrm{pN} 2$ is discovered intraoperatively, as patients with clinically staged N0-N1 disease are unlikely to have received neoadjuvant therapy. In these cases, however, completion of the planned resection is still recommended; some studies of the efficacy of adjuvant therapy after resection for occult $\mathrm{pN} 2$ disease have found survival rates comparable to those with known cN2 disease receiving neoadjuvant therapy $(7,9,10)$.

The hypothesis of this study is that patients with residual disease that receive non-guideline concordant adjuvant therapy would experience lower survivals than patients that receive guideline-concordant care. Furthermore, it is hypothesized that patients with $\mathrm{pN} 2$ disease, reflecting a systemic burden of disease, would experience lower survivals than patients with positive margins, which reflect local extension of disease. In this study, the survivals of patients with these two forms of postoperative residual diseasepositive surgical margins and occult $\mathrm{pN} 2$ disease-were compared.

We present the following article in accordance with the STROBE reporting checklist (available at http://dx.doi. org/10.21037/jtd-21-110).

\section{Methods}

\section{Data source}

The National Cancer Database (NCDB) is a hospitalbased clinical oncology tumor registry maintained as a joint effort of the American College of Surgeons (ACS) and the American Cancer Society. The NCDB contains more than 34 million records of patients with cancer obtained from more than 1500 Commission of Cancer (CoC) accredited facilities, representing approximately $70 \%$ of patients diagnosed annually with cancer.

\section{Study population}

The NCDB Participant User Data File was queried for patients 18 years or older who were diagnosed with NSCLC from 2006 to 2016 and had received no preoperative radiation therapy or chemotherapy. Patients were evaluated if they underwent curative intent surgical resection of clinical stage T1-3N0-1M0 NSCLC and were found to have positive margins, occult pathologic N2 disease (pN2), or both. Patients with clinical T descriptors of 0 or 4, unknown clinical $\mathrm{T}$ or $\mathrm{N}$ descriptors, or metastatic disease (M1) were excluded. T4 tumors were excluded as they are frequently "bulky" and/or have extensive mediastinal involvement that requires upfront neoadjuvant chemotherapy or chemoradiation. Patients with pathologic $\mathrm{T}$ descriptors of IS or $\mathrm{X}$ were also excluded (Figure 1). The study was conducted in accordance with the Declaration of Helsinki (as revised in 2013).

\section{Variables and outcomes}

Demographic variables included sex, race, age, income, education, insurance, facility type, distance from nearest treatment facility, and type of residence. Clinical and tumor specific variables included CharlsonDeyo score, histology, tumor size $(\leq 3,3-5,5-7$, and $>7 \mathrm{~cm}$ ), year of diagnosis and receipt of guideline- 


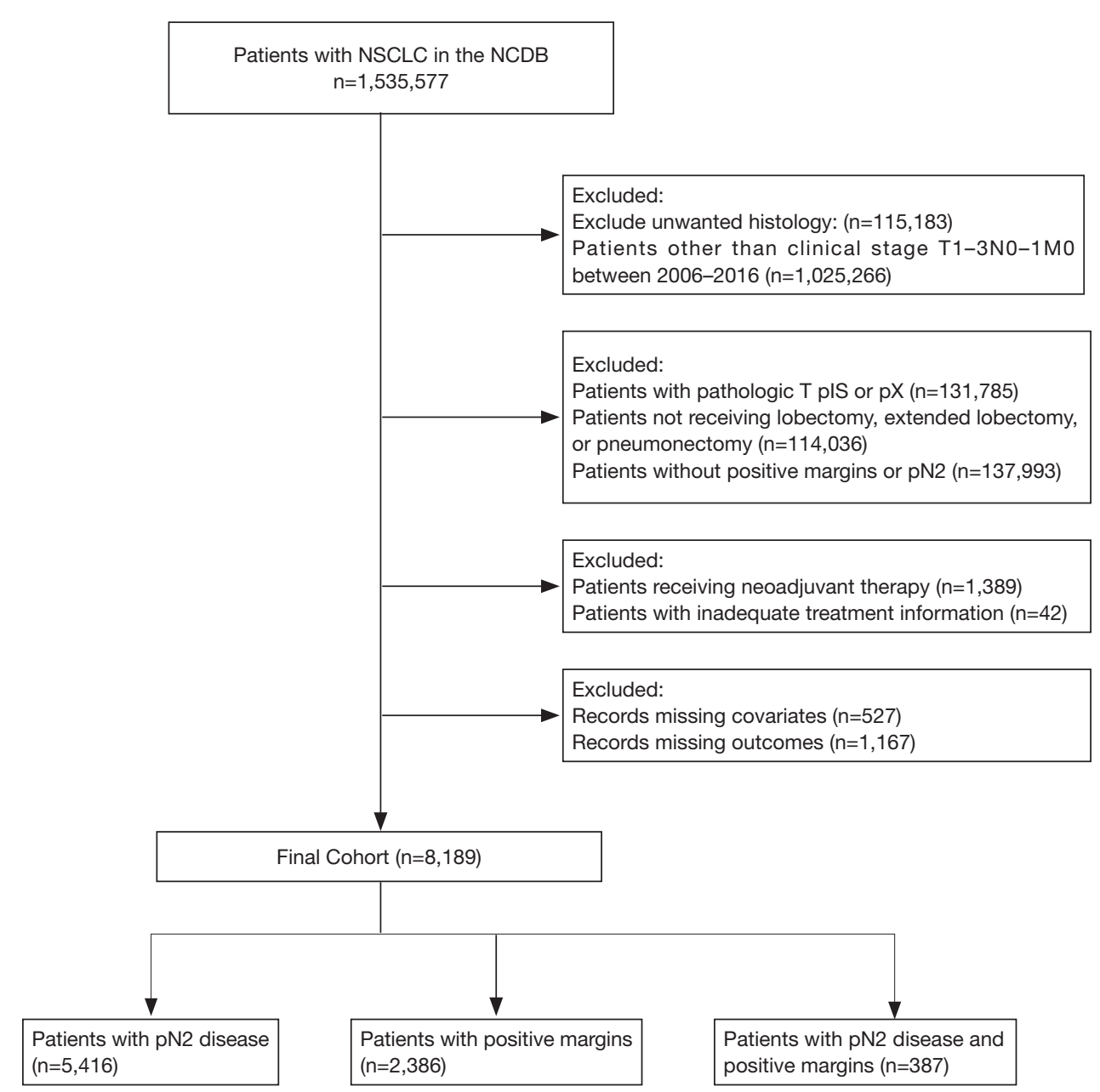

Figure 1 Consort Diagram showing cohort selection process. The final cohort contained 8,189 patients, who were categorized into three separate cohorts depending on the form of residual disease-occult pN2 disease, positive margins, or both.

concordant adjuvant therapy (Table 1). Histology was subdivided into adenocarcinoma, squamous cell carcinoma, and other. Age was categorized by quartiles based on median and interquartile range. The tumor size cutoffs were chosen because they represent the tumor size cutoffs for NSCLC staging according to the TNM system. The extent of surgical resection was also identified and recordedprocedures were stratified into lobectomies, extended lobectomies (resection of a single lobe plus a segment of another lobe), and pneumonectomies. Sublobar resections were excluded as they were felt to be inadequate for larger tumors.

Patients were grouped based upon form of residual disease-occult $\mathrm{pN} 2$ disease, positive margins, or both. Type of positive margin was subdivided into R1 vs. R2 disease for supplemental analysis but was not subdivided in the primary multivariable analysis. Patients were categorized as having received guideline-concordant or non-guideline concordant care based on criteria listed in Table 1. Patients with residual disease were included in their respective cohorts regardless of whether or not they received guidelineconcordant or non-guideline concordant treatment in order to fully capture the totality of the patient population with remaining residual disease after surgical resection. The primary outcome of interest was five-year overall survival, defined as the interval from the date of surgery to the date of last contact or last vital status. 30 and 90-day mortalities were not analyzed in order to avoid immortal time bias.

\section{Statistical analysis}

Descriptive analysis was used to report frequencies and 
Table 1 Criteria for categorization of guideline-concordant treatment

\begin{tabular}{|c|c|c|c|}
\hline & pNO & $\mathrm{pN} 1$ & pN2 \\
\hline T1abc & $\mathrm{R} \pm \mathrm{C}$ & $\mathrm{CR}$ & $\mathrm{CR}$ \\
\hline $\mathrm{T} 2 \mathrm{ab}$ & $\mathrm{R} \pm \mathrm{C}$ & $\mathrm{CR}$ & CR \\
\hline T3 & CR & CR & CR \\
\hline T1abc & Not studied & Not studied & $C \pm R$ \\
\hline T2ab & Not studied & Not studied & $\mathrm{C} \pm \mathrm{R}$ \\
\hline T3 & Not studied & Not studied & $\mathrm{C} \pm \mathrm{R}$ \\
\hline
\end{tabular}

Criteria based on form of adjuvant chemotherapy or radiation: Double-agent adjuvant chemotherapy; Radiation dosage $>45$ Gy; Radiation dosage volume $>25$ fractions; Radiation indicated for lung or chest, as defined by the NCDB; Radiation duration $<180$ days. CR $=$ chemotherapy and radiation. $\mathrm{RC}=$ radiation, with or without chemotherapy. $\mathrm{C} \pm \mathrm{R}=$ chemotherapy, with or without radiation

percentages for all categorical variables for each of the three cohorts. Demographic and clinical characteristics of the three groups were compared using Chi-Square and Fisher's exact test when appropriate. The KaplanMeier method was used to generate five-year survival curves; strata were compared using the log-rank test. Propensity match analysis was not performed due to violations of the propensity score match assumption. To analyze the independent effect of type of occult residual disease on survival, a multivariable Cox regression model was generated to estimate hazard ratios for the aforementioned variables. Patients with missing covariate information, follow-up time, or living status were excluded for multivariable analysis. All variables were considered initially for the multivariable model, and variables with $\mathrm{P}>0.05$ not acting as confounders, with $>10 \%$ change in hazard ratio of residual disease were excluded from the final multivariable analysis; form of residual disease was forced into the final model as this was the primary variable of interest. Post hoc analysis testing interaction between form of residual disease and treatment concordance was significant and remained in the model. Landmark analysis of 30- and 90-day mortality post-surgery were tested separately as sensitivity analysis to account for potential immortal time bias. Results were similar to main results. For simplicity, only the main results were reported. Schoenfeld residuals were used to test proportional hazard assumption for Cox models. Statistical significance was set at two-sided $\mathrm{P}<0.05$. Statistical analysis and graphics were performed and generated using SAS 9.4 (SAS Institute, Cary, NC).

\section{Results}

A total of 8,189 patients fit the inclusion criteria (Figure 1). $66 \%(5,416)$ of these patients had occult pN2 disease, of which $66.4 \%(3,597)$ received guideline-concordant adjuvant therapy. $29 \%(2,386)$ had positive surgical margins postoperatively, of which $18.9 \%$ (451) received guidelineconcordant adjuvant therapy. 5\% (387) had both positive surgical margins and occult pN2 disease, of which 20.4\% (79) received guideline-concordant adjuvant therapy (Table 2).

Patients who had occult pN2 disease had a mean age of 67 years (SD 9.6 years), were more likely to be female (53.7\%), had a higher proportion of smaller tumor sizes $(49.3 \%$ with size $<3 \mathrm{~cm})$, were more likely to have received a lobectomy $(89.1 \%)$, and had the highest proportion of Charlson-Deyo score $=0$ (52.3\%). Patients who had positive margins had a mean age of 68 years (SD 9.5 years), were more likely to be male (56.2\%), were more likely to be white $(88.9 \%)$ and were least likely to have CharlsonDeyo score $=0(47.2 \%)$. Patients with both occult pN2 disease and positive margins had a mean age of 69 years (SD 10.2 years), were more likely to be non-white (13.95\%), were most likely to have received a pneumonectomy $(15.76 \%)$ and were most likely to have larger tumor sizes $(14.73 \%$ with size $>7 \mathrm{~cm})$. A full breakdown of cohort characteristics can be found in Table 2. Patients with pN2 disease receiving adjuvant therapy had a median treatment start date 59 days after surgery (IQR: 42-126 days). Patients with positive margins receiving adjuvant therapy had a median treatment start date 56 days after surgery (IQR: 
Table 2 Demographics and clinical characteristics of NCDB patients

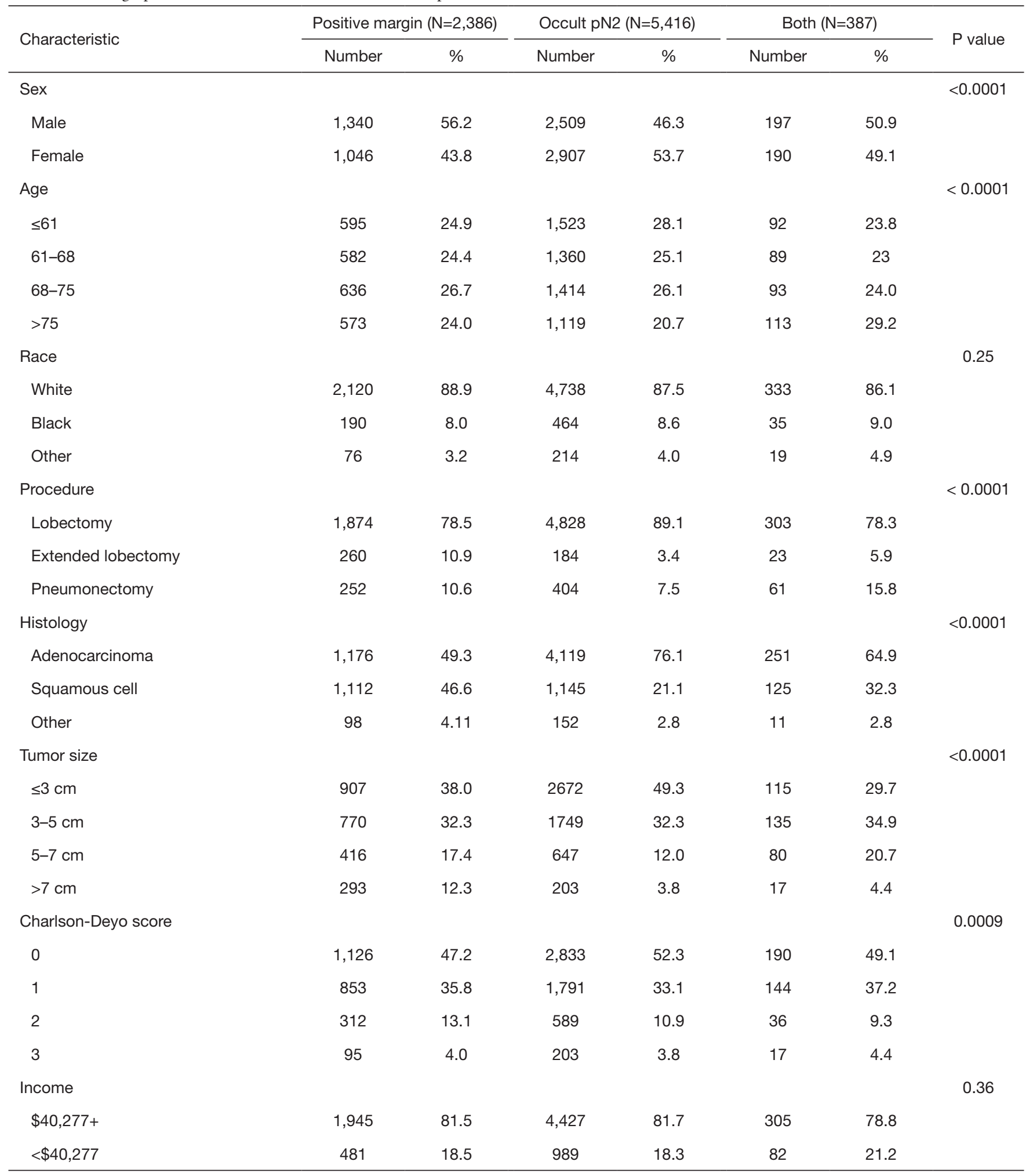

Table 2 (continued) 
Table 2 (continued)

\begin{tabular}{|c|c|c|c|c|c|c|c|}
\hline Characteristic & \multicolumn{2}{|c|}{ Positive Margin ( $\mathrm{N}=2,386)$} & \multicolumn{2}{|c|}{ Occult pN2 $(\mathrm{N}=5,416)$} & \multicolumn{2}{|c|}{ Both $(\mathrm{N}=387)$} & $P$ value \\
\hline Education & & & & & & & 0.16 \\
\hline$<17.6 \%$ & 1,905 & 79.8 & 4,381 & 80.9 & 299 & 77.3 & \\
\hline$>17.6 \%$ & 481 & 20.2 & 1,035 & 19.1 & 88 & 22.7 & \\
\hline Not insured & 44 & 1.8 & 94 & 1.7 & DS & DS & \\
\hline Private insurance/managed care & 665 & 27.8 & 1,737 & 32.1 & 96 & 24.8 & \\
\hline Medicaid & 138 & 5.8 & 301 & 5.6 & 17 & 4.4 & \\
\hline Medicare & 1,512 & 63.4 & 3,205 & 59.2 & 259 & 66.9 & \\
\hline Community Cancer Program & 231 & 9.7 & 331 & 6.11 & 28 & 7.2 & \\
\hline $\begin{array}{l}\text { Comprehensive Community Cancer } \\
\text { Program }\end{array}$ & 1,105 & 46.3 & 2,257 & 41.7 & 163 & 42.1 & \\
\hline Academic/Research Program & 730 & 30.6 & 1,976 & 36.5 & 127 & 32.8 & \\
\hline Integrated Network Cancer Program & 320 & 13.4 & 852 & 15.7 & 69 & 17.98 & \\
\hline Distance & & & & & & & 0.52 \\
\hline$>12.5$ miles & 1,086 & 45.5 & 2,501 & 46.2 & 188 & 48.6 & \\
\hline$\leq 12.5$ miles & 1,300 & 54.5 & 2,915 & 53.8 & 199 & 51.4 & \\
\hline Yes & 1,134 & 47.5 & 3,993 & 73.7 & 261 & 67.4 & \\
\hline No & 1,252 & 52.5 & 1,423 & 26.3 & 126 & 32.6 & \\
\hline Adjuvant radiation & & & & & & & $<0.0001$ \\
\hline Yes & 952 & 39.9 & 1,928 & 35.6 & 178 & 76.0 & \\
\hline No & 1,434 & 60.1 & 3,488 & 64.4 & 209 & 54.0 & \\
\hline AJCC clinical N stage & & & & & & & 0.002 \\
\hline No & 1,897 & 79.5 & 4,261 & 78.7 & 277 & 71.6 & \\
\hline N1 & 489 & 20.5 & 1,155 & 21.3 & 110 & 28.4 & \\
\hline
\end{tabular}

Table 2 (continued) 
Table 2 (continued)

\begin{tabular}{|c|c|c|c|c|c|c|c|}
\hline Characteristic & \multicolumn{2}{|c|}{ Positive Margin $(\mathrm{N}=2,386)$} & \multicolumn{2}{|c|}{ Occult pN2 $(\mathrm{N}=5,416)$} & \multicolumn{2}{|c|}{ Both $(\mathrm{N}=387)$} & $P$ value \\
\hline \multicolumn{8}{|l|}{ Surgical margins status at any CoC facility } \\
\hline Negative & 0 & 0 & 5,416 & 100 & 0 & 0 & \\
\hline $\mathrm{R} 1$ & 2,251 & 94.3 & 0 & 0 & 365 & 94.3 & \\
\hline \multicolumn{8}{|l|}{ AJCC pathologic $\mathrm{N}$} \\
\hline $\mathrm{p} 0$ & 1,508 & 63.2 & 0 & 0 & 0 & 0 & \\
\hline $\mathrm{p} 1$ & 878 & 36.8 & 0 & 0 & 0 & 0 & \\
\hline $\mathrm{p} 2$ & 0 & 0 & 5,416 & 100 & 387 & 100 & \\
\hline Non-concordant & 1,935 & 81.1 & 1,819 & 33.6 & 308 & 79.6 & \\
\hline Treatment type & & & & & & & $<0.0001$ \\
\hline $\begin{array}{l}\text { Surgery + adjuvant chemoradiation } \\
\text { Therapy }\end{array}$ & 642 & 26.9 & 1,790 & 33.1 & 155 & 40.1 & \\
\hline Surgery + adjuvant chemotherapy & 492 & 20.6 & 2,203 & 40.7 & 106 & 27.4 & \\
\hline Surgery + adjuvant radiation therapy & 310 & 13.0 & 138 & 2.6 & 23 & 5.9 & \\
\hline Surgery alone & 942 & 39.5 & 1,285 & 23.7 & 103 & 26.6 & \\
\hline
\end{tabular}

42-82 days). Patients with both $\mathrm{pN} 2$ and positive margins receiving adjuvant therapy had a median treatment start date 52 days after surgery (IQR: 40-95 days). Patients who received both chemotherapy and radiation had a median onset of the latter of the two therapies by day 45 after surgery (IQR: 35-57 days).

The highest observed five-year survival among all patients with residual disease, regardless of receipt of guideline-concordant care, was the occult $\mathrm{pN} 2$ group (35.8\%), followed by the positive margin group (33.9\%). Patients with both occult $\mathrm{pN} 2$ disease and positive margins had the lowest overall survival (22.9\%) (Figure 2A). Among patients receiving guideline-concordant care $(\mathrm{P}=0.07)$, fiveyear survival was highest in the occult pN2 group (42.2\%), followed by the positive margin group (36.9\%), with the lowest overall survival rate being observed in patients with both forms of residual disease (31.6\%) (Figure 2B). Among patients receiving non-guideline concordant care $(\mathrm{P}<0.0001)$, five-year survival was highest in the positive margin group $(33.3 \%)$, followed by the occult pN2 group $(23.5 \%)$, with the lowest overall survival rate being observed in patients with both forms of residual disease (20.7\%) (Figure 2C). No significant difference in overall survival was seen between patients with $\mathrm{R} 1$ positive margins and $\mathrm{R} 2$ positive margins (32.6\% vs. 27.4\%, $\mathrm{P}=0.27$ ) (Data not shown). Among patients with positive margins, nodal status was associated with overall survival within the overall patient group (pN0 OS $38.0 \%$, pN1 OS $26.6 \%$, pN2 OS $22.9 \%, \mathrm{P}<0.0001)$ as well as the non-guideline concordant group (pN0 OS $37.9 \%$, pN1 OS $25.2 \%$, pN2 OS $20.7 \%$, $\mathrm{P}<0.0001)$, but was not associated with overall survival within the guideline-concordant group (pN0 OS 39.3\%, pN1 OS 32.1\%, pN2 OS 31.6\%, $\mathrm{P}<0.52$ ) (Figure 3).

A Cox proportional hazard model was performed to identify the prognostic factors for overall survival. Compared to $\mathrm{pN} 2$, patients with positive margins had a $\mathrm{HR}=0.73$ (95\% CI: $0.68,0.79, \mathrm{P}<0.0001$ ), while the "both" group had a HR=1.06 (95\% CI: 0.93, 1.21, P=0.38) (Table 3). Post hoc analysis accounting for the interaction between form of residual disease and treatment concordance found that non-guideline concordant treatment was associated with increased risk of mortality for all forms 
A
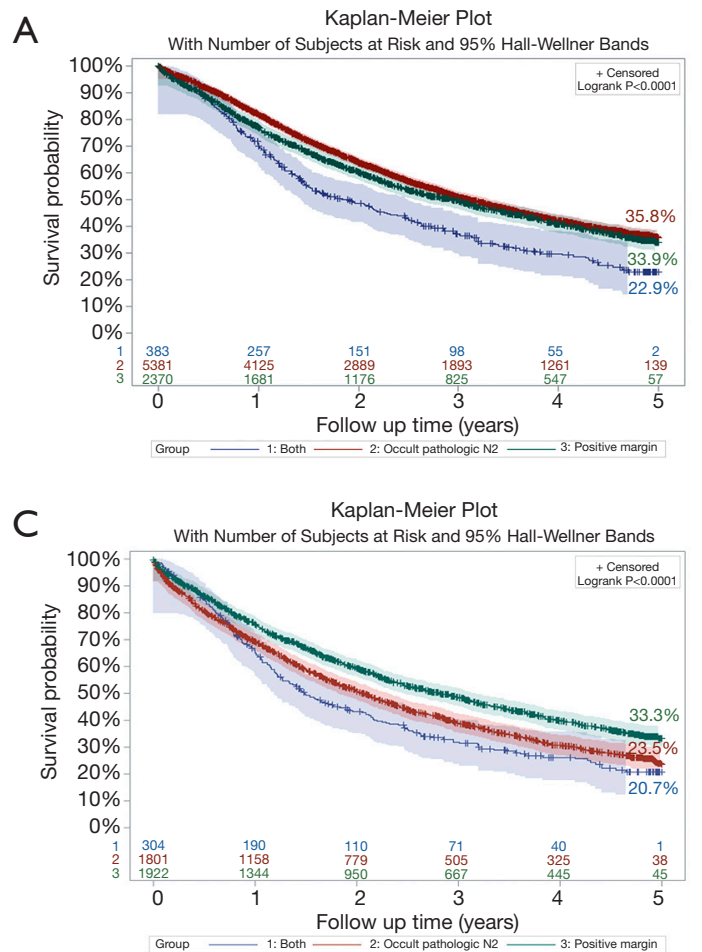

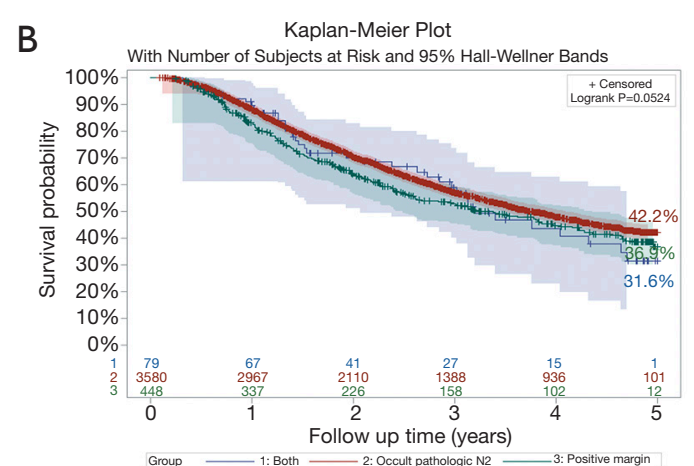

Figure 2 Kaplan-Meier analysis of overall survival by form of residual disease. (A) Overall survival of all patients, regardless of receipt of concordant or non-guideline concordant care. Patients with occult pN2 disease only have the highest overall survival (35.8\%), followed by patients with positive margins only (33.9\%). Patients with both positive margins and occult pN2 disease have the lowest overall survival (22.9\%) $(\mathrm{P}<0.0001)$. (B) Overall survival of patients receiving guideline-concordant care. Patients with occult pN2 disease only have the highest overall survival (42.2\%), followed by patients with positive margins only (36.9\%). Patients with both positive margins and occult $\mathrm{pN} 2$ disease have the lowest overall survival (31.6\%), though these survival differences are not statistically significant $(\mathrm{P}=0.052)$. $(\mathrm{C}) \mathrm{Overall}$ survival of patients receiving non-guideline concordant care. Patients with positive margins only have the highest overall survival (33.3\%), followed by patients with occult pN2 disease only (23.5\%). Patients with both positive margins and occult pN2 disease have the lowest overall survival $(20.7 \%)(\mathrm{P}<0.0001)$.

of residual disease, though the magnitude of the effect of concordance differed by group (Table 4). For positive margins, the non-concordant cohort had a $\mathrm{HR}=1.25$ (95\% CI: 1.08, 1.45, $\mathrm{P}=0.0027$ ); for $\mathrm{pN} 2$ disease, the nonconcordant group had a HR =1.71 (95\% CI: $1.58,1.85$, $\mathrm{P}<0.0001)$; for the "both" group, the non-concordant group had a HR $=1.85$ (95\% CI: 1.30, 2.62, P=0.0006).

After adjusting for patient demographics and other clinical characteristics, age greater than the median of 68 years, "other" race categorization, extended lobectomy and pneumonectomy, non-adenocarcinoma histology, tumor size $>3 \mathrm{~cm}$, Charlson-Deyo score $>0$, treatment at a comprehensive community cancer program, and nonguideline concordant treatment were associated with increased risk of mortality. Positive margins, female sex, and private insurance were associated with decreased risk of mortality. The hazard ratios and $95 \%$ confidence intervals for all significant factors are shown in Table 3.

\section{Conclusions}

The findings from this study demonstrate a markedly increased mortality rate in patients who receive nonguideline concordant care in comparison to those who receive guideline-concordant care in the setting of residual disease after surgical resection of NSCLC. Though it can only be speculated as to why patients did not receive guideline-concordant care, a significant proportion of patients in our study did not receive guidelineconcordant adjuvant therapy, with roughly one-third of 
A

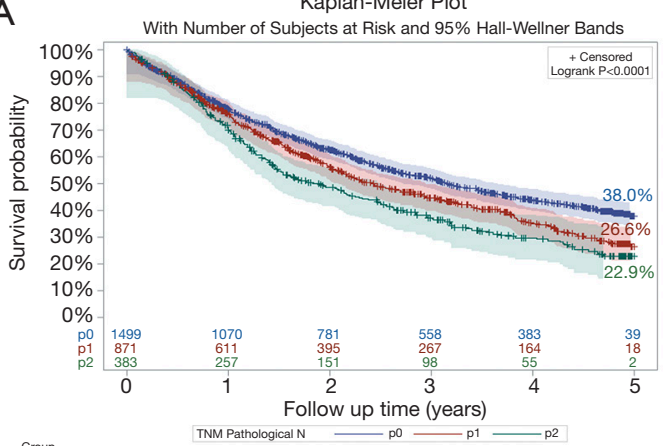

Group

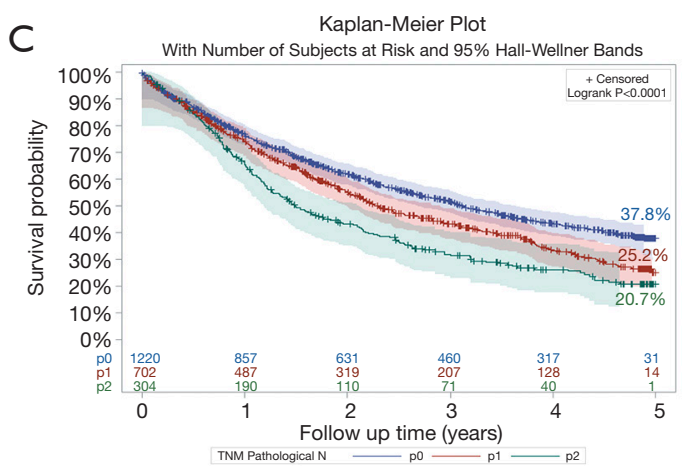

B

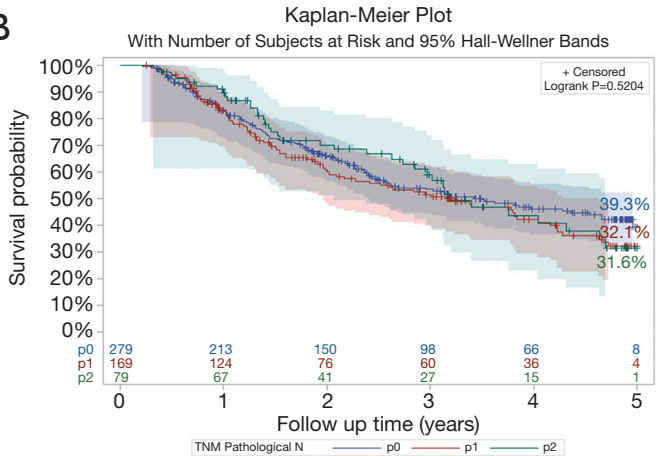

Figure 3 Kaplan-Meier analysis of overall survival for patients with positive margins stratified by pathologic N status. (A) Overall survival of all patients with positive margins stratified by pathologic $\mathrm{N}$ status. Patients with pN0 have the highest overall survival (38.0\%), followed by patients with $\mathrm{pN} 1$ disease (26.6\%). Patients with $\mathrm{pN} 2$ disease have the lowest overall survival $(22.9 \%)(\mathrm{P}<0.0001)$. (B) Overall survival of patients with positive margins who received guideline-concordant adjuvant therapy, stratified by pathologic $\mathrm{N}$ status. Patients with pN0 have the highest overall survival (39.3\%), followed by patients with pN1 disease (32.1\%). Patients with pN2 disease have the lowest overall survival (31.6\%) $(\mathrm{P}=0.52)$. (C) Overall survival of patients with positive margins who received non-guideline concordant adjuvant therapy, stratified by pathologic $\mathrm{N}$ status. Patients with pN0 have the highest overall survival (37.8\%), followed by patients with pN1 disease (25.2\%). Patients with pN2 disease have the lowest overall survival $(20.7 \%)(\mathrm{P}<0.0001)$.

patients with occult pN2 disease and roughly $80 \%$ of patients with positive margins or both positive margins and $\mathrm{pN} 2$ disease receiving non-guideline concordant care. Furthermore, the findings suggest that patients with occult $\mathrm{pN} 2$ disease after resection, which may represent the systemic spread of disease, have poorer overall survival than patients with positive margins after resection, which may represent local extension of disease. Understanding that there is heterogeneity in the operations performed in this analysis, the cohort was restricted to patients who underwent lobectomy or pneumonectomy, as they reflect commonly performed curative-intent operations that can result in either positive margins or positive N2 disease, which can pose clinical challenges in management. Interestingly, patients undergoing extended lobectomies or pneumonectomies were observed to have a disproportionately high incidence of positive margins. Though the exact cause of this phenomenon is unknown, it is plausible that the disproportionately high incidence of positive margins in the extended lobectomy group, in part, may be attributed to a hesitancy to perform a pneumonectomy due to possible pre-existing systemic illness or adverse cardiopulmonary status, at the expense of leaving behind a positive surgical margin.

In this study, the reported five-year overall survival of patients with occult $\mathrm{pN} 2$ disease who received guidelineconcordant adjuvant chemotherapy of $42.2 \%$ was within the range of five-year survivals for patients with occult $\mathrm{pN} 2$ disease (i.e., cN0 and cN1, pN2) previously reported by other studies which ranged from $30 \%$ to $51.2 \%$ (11-16). The reported five-year overall survival of $36.9 \%$ of patients with positive margins receiving guideline-concordant care 
Table 3 Cox Proportional Hazards Model for Independent Predictors of Mortality

\begin{tabular}{|c|c|c|}
\hline Covariate & Hazard Ratio (95\% Cl) & P-value \\
\hline \multicolumn{3}{|l|}{ Group } \\
\hline pN2 & Reference & \\
\hline Positive Margins & $0.729(0.676-0.787)$ & $<0.0001$ \\
\hline Both & $1.062(0.929-1.214)$ & 0.38 \\
\hline \multicolumn{3}{|l|}{ Age } \\
\hline$\leq 61$ & Reference & \\
\hline $61-68$ & $1.046(0.951-1.151)$ & 0.36 \\
\hline $68-75$ & $1.149(1.037-1.273)$ & 0.008 \\
\hline$>75$ & $1.390(1.250-1.546)$ & $<0.0001$ \\
\hline \multicolumn{3}{|l|}{ Race } \\
\hline White & Reference & \\
\hline Black & $0.944(0.843-1.056)$ & 0.31 \\
\hline Other & $0.660(0.547-0.796)$ & $<0.0001$ \\
\hline \multicolumn{3}{|l|}{ Sex } \\
\hline Male & Reference & \\
\hline Female & $0.744(0.699-0.792)$ & $<0.0001$ \\
\hline \multicolumn{3}{|l|}{ Procedure } \\
\hline Lobectomy & Reference & \\
\hline Extended Lobectomy & $1.455(1.291-1.639)$ & $<0.0001$ \\
\hline Pneumonectomy & $1.130(1.016-1.258)$ & 0.025 \\
\hline \multicolumn{3}{|l|}{ Histology } \\
\hline Adenocarcinoma & Reference & \\
\hline Squamous Cell & $1.104(1.029-1.185)$ & 0.006 \\
\hline Other & $1.219(1.037-1.443)$ & 0.02 \\
\hline \multicolumn{3}{|l|}{ Tumor size } \\
\hline$\leq 3$ & Reference & \\
\hline $3-5 \mathrm{~cm}$ & $1.182(1.101-1.269)$ & $<0.0001$ \\
\hline $5-7 \mathrm{~cm}$ & $1.318(1.201-1.446)$ & $<0.0001$ \\
\hline $7+\mathrm{cm}$ & $1.759(1.582-1.957)$ & $<0.0001$ \\
\hline \multicolumn{3}{|l|}{ Charlson-Deyo Score } \\
\hline 0 & Reference & \\
\hline 1 & $1.156(1.082-1.236)$ & $<0.0001$ \\
\hline 2 & $1.14(1.034-1.257)$ & 0.008 \\
\hline $3+$ & $1.522(1.316-1.76)$ & $<0.0001$ \\
\hline
\end{tabular}

Table 3 (continued)
Table 3 (continued)

\begin{tabular}{|c|c|c|}
\hline Covariate & Hazard Ratio (95\% Cl) & P-value \\
\hline \multicolumn{3}{|l|}{ Insurance } \\
\hline Medicare & Reference & \\
\hline Medicaid & $1.027(0.888-1.188)$ & 0.72 \\
\hline Other Government & $0.964(0.752-1.235)$ & 0.77 \\
\hline Private Insurance & $0.840(0.772-0.914)$ & $<0.0001$ \\
\hline Not Insured & $1.157(0.920-1.455)$ & 0.21 \\
\hline \multicolumn{3}{|l|}{ Facility type } \\
\hline $\begin{array}{l}\text { Academic/Research } \\
\text { Program }\end{array}$ & Reference & \\
\hline $\begin{array}{l}\text { Community Cancer } \\
\text { Program }\end{array}$ & $1.056(0.934-1.196)$ & 0.38 \\
\hline $\begin{array}{l}\text { Comprehensive } \\
\text { Community Cancer } \\
\text { Program }\end{array}$ & $1.167(1.089-1.25)$ & $<0.0001$ \\
\hline $\begin{array}{l}\text { Integrated Network Cancer } \\
\text { Program }\end{array}$ & $1.085(0.987-1.193)$ & 0.09 \\
\hline \multicolumn{3}{|l|}{ Treatment Concordance } \\
\hline Concordant & Reference & \\
\hline Non-concordant & $1.610(1.504-1.725)$ & $<0.0001$ \\
\hline
\end{tabular}

reported in the current study is within the range of survival rates previously reported, which range from $20 \%$ to $38.5 \%$ (4,6,17-19). The five-year overall survival for patients with both positive margins and occult $\mathrm{pN} 2$ who received guideline-concordant care in this study was $31.6 \%$-no other studies were identified that analyzed the survival of patients with both forms of residual disease. While an $\mathrm{N} 2$ node in isolation is known to be a significant driver of mortality, the addition of a positive margin may further increase the burden of disease.

Currently there are a lack of universally accepted clinical guidelines regarding adjuvant therapy following discovery of residual disease. In this study, patients with occult $\mathrm{pN} 2$ disease who received adjuvant chemotherapy were clustered with patients receiving adjuvant chemoradiation based on the idea that N2 disease represents the systemic spread of disease and, therefore, should be treated primarily with systemic therapy rather than local radiation therapy. This theory is supported by existing clinical practice guidelinesNCCN guidelines for patients with R0 resections and occult $\mathrm{pN} 2$ disease recommend adjuvant chemotherapy with or 
Table 4 Cox proportional hazards model for independent predictors of mortality when accounting for interaction between residual disease group and treatment concordance

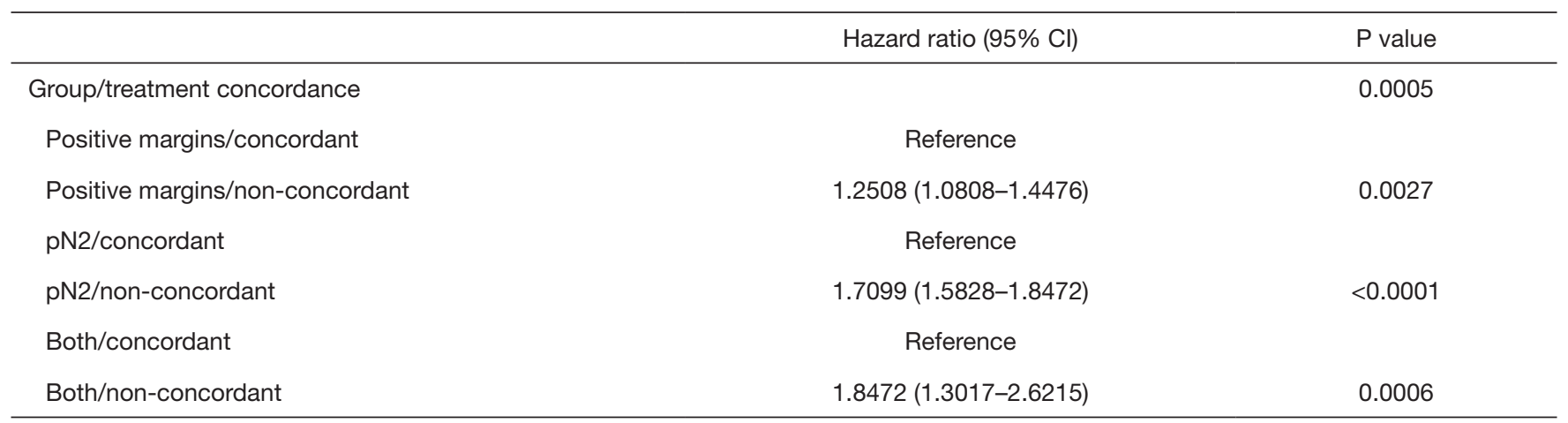

without radiotherapy (7). Efficacy of adjuvant radiotherapy, however, is questionable-guidelines from the American Society for Radiation Oncology note that current clinical evidence suggests that addition of PORT to N2 disease with R0 resections "does not improve overall survival but may improve local control when compared with observation strategies (8)." A recent randomized Phase II trial by Sun et al. found no survival benefit for adjuvant concurrent chemoradiotherapy compared with adjuvant platinum-based chemotherapy alone (20). This finding has been supported by previous retrospective studies as well that suggest that there are no overall survival benefits to addition of adjuvant radiotherapy versus adjuvant chemotherapy alone $(10,13,21)$. The findings of Sun et al. must be interpreted cautiously, however, as sequential radiotherapy administered after adjuvant chemotherapy, rather than concurrent chemoradiotherapy, is more frequently performed $(8,22,23)$.

Similarly, patients with positive margins were clustered if they received adjuvant radiotherapy with or without chemotherapy, as positive margins represent local spread of disease that can be treated with local radiotherapy. For the purposes of this study, both R1 and R2 resections were considered to be "positive margins" and were analyzed together. Because the two forms have been considered by some to be characteristically different, a supplementary analysis was performed to compare survival of patients with R1 positive margins against patients with R2 positive margins $(9,24)$. No significant difference in overall survival was found between the two groups (data not shown, $\mathrm{P}=0.27$ ). Current clinical guidelines regarding the efficacy of addition of systemic therapy to patients with positive margins lack clear consensus and are contradicted by recent studies. NCCN guidelines currently recommend either re-resection or adjuvant radiation therapy for R1 and R2 resections in patients with findings up to Stage IIA, as well as the addition of adjuvant chemotherapy for patients up to Stage IIIB (7). ACCP guidelines however recommend only adjuvant radiation therapy for $\mathrm{R} 1$ resections in patients with Stage I or II NSCLC (25). Wang et al. substantiated the use of adjuvant radiation therapy in patients with positive margins after undergoing a lobectomy or pneumonectomy for Stage II or III NSCLC, finding that the use of PORT was an independent predictor of five-year overall survival (18). In contrast to current clinical guidelines, Hancock et al. suggested that adjuvant chemotherapy alone was the most effective form of postoperative treatment of Stage I disease with positive margins with no statistically significant differences found for adjuvant radiation therapy alone or adjuvant chemoradiation therapy (3). In the same vein, Smeltzer et al. suggested that chemotherapy alone was the most effective adjuvant therapy for early-stage N0 patients with positive margins, while chemotherapy or chemoradiation therapy were associated with longer survival for patients with advanced stages of disease (19).

There are obvious limitations associated with this retrospective study inherent to using the NCDBassignment of patients to various forms of adjuvant therapy was unobserved and therefore susceptible to uncontrolled confounding factors (26). Current guidelines also recommend re-resection as an alternative to adjuvant therapy (7). Unfortunately, a comparison of patients undergoing re-resection $v s$. adjuvant therapy for positive margins could not be performed owing to the fact that the NCDB does not capture data on re-resections. The NCDB also does not currently contain patient data on pre-operative mediastinal staging, characterization of $\mathrm{pN} 2$ disease, location of positive margins, pulmonary function tests, performance status, or specific comorbidities, which 
admittedly could be used to better stratify patients into homogenous cohorts and identify independent predictors of survival (27-29). The NCDB also lacks data regarding clinical reasoning behind the selection of adjuvant therapy, completion of therapy, and sequencing of therapy. It is not known whether patients who did not receive adjuvant therapy may have had risk factors that both precluded receipt of chemotherapy and predisposed them to higher mortality. While different clinical circumstances may warrant the administration of chemoradiation therapy in either a sequential or concurrent manner, current guidelines allow for either approach to be employed; thus, both were included in this study. It is acknowledged that these limitations are significant, but a registry with the breadth of information such as the NCDB has yet to be developed and employed to raise the issue in this report. Furthermore, the database has been employed at the individual participating institutions to assess their own quality metrics in other diseases; therefore, its use in assessing guideline concordance, another measure of quality, is not without precedent.

Though prior studies have independently analyzed long-term survival of N2 disease or positive margins independently, no study has comparatively analyzed both forms of residual disease using the same cohort or looked at the combined effects of having both occult N2 disease and positive margins. The findings of this study underscore the importance of adherence to guideline-concordant adjuvant therapy in the setting of residual disease after surgical resection of primary NSCLC. The deleterious effects of non-guideline concordant care seen in all three patient groups in this study, combined with the large percentage of patients that did not receive guideline-concordant care, indicate that there are a substantial number of lung cancer patients who may further benefit from optimized medical care. The secondary finding of this study-that patients with positive margins fare better than those with $\mathrm{pN} 2$ disease-reinforces the notion that occult $\mathrm{pN} 2$ disease is a systemic process that is best targeted with systemic adjuvant chemotherapy.

\section{Acknowledgments}

Manuscript was accepted to be read at the $100^{\text {th }}$ Annual Meeting of the American Association for Thoracic Surgery, New York, NY (Cancelled due to the COVID-19 pandemic). The data used in this study are derived from a deidentified NCDB file. The ACS and the CoC have not verified and are not responsible for the analytic or statistical methodology employed, or the conclusions drawn from these data by the investigator.

Funding: Li Ding was supported by the National Center for Advancing Translational Science (NCATS) of the U.S. National Institutes of Health, grant numbers [UL1TR001855] and [UL1TR000130].

\section{Footnote}

Reporting Checklist: The authors have completed the STROBE reporting checklist. Available at http://dx.doi. org/10.21037/jtd-21-110

Peer Review File: Available at http://dx.doi.org/10.21037/jtd$21-110$

Conflicts of Interest: All authors have completed the ICMJE uniform disclosure form (available at http:// dx.doi.org/10.21037/jtd-21-110). LD is funded by grants UL1TR001855 from the National Center for Advancing Translational Science (NCATS) of the U.S. National Institutes of Health. AWK serves as an unpaid editorial board member of Fournal of Thoracic Disease from Jan 2020 to Dec 2021. PMM serves as an unpaid editorial board member of Fournal of Thoracic Disease from Apr 2020 to Mar 2022. The other authors have no conflicts of interest to declare.

Ethical Statement: The authors are accountable for all aspects of the work in ensuring that questions related to the accuracy or integrity of any part of the work are appropriately investigated and resolved. The study was conducted in accordance with the Declaration of Helsinki (as revised in 2013).

Open Access Statement: This is an Open Access article distributed in accordance with the Creative Commons Attribution-NonCommercial-NoDerivs 4.0 International License (CC BY-NC-ND 4.0), which permits the noncommercial replication and distribution of the article with the strict proviso that no changes or edits are made and the original work is properly cited (including links to both the formal publication through the relevant DOI and the license). See: https://creativecommons.org/licenses/by-nc-nd/4.0/.

\section{References}

1. Siegel RL, Miller KD, Jemal A. Cancer statistics, 2020. 
CA Cancer J Clin 2020;70:7-30.

2. Detterbeck FC, Lewis SZ, Diekemper R, et al. Executive Summary. Chest 2013;143:7S-37S.

3. Hancock JG, Rosen JE, Antonicelli A, et al. Impact of adjuvant treatment for microscopic residual disease after non-small cell lung cancer surgery. Ann Thorac Surg 2015;99:406-13.

4. Riquet M, Achour K, Foucault C, et al. Microscopic Residual Disease After Resection for Lung Cancer: A Multifaceted but Poor Factor of Prognosis. Ann Thorac Surg 2010;89:870-5.

5. Wind J, Smit E, Senan S, et al. Residual disease at the bronchial stump after curative resection for lung cancer. Eur J Cardiothorac Surg 2007;32:29-34.

6. Gulack BC, Cox ML, Yang CFJ, et al. Survival after radiation for stage I and II non-small cell lung cancer with positive margins. J Surg Res 2018;223:94-101.

7. NCCN. Non-Small Cell Lung Cancer: NCCN Guidelines with NCCN Evidence Blocks. National Comprehensive Cancer Network 2019.

8. Rodrigues G, Choy H, Bradley J, et al. Adjuvant radiation therapy in locally advanced non-small cell lung cancer: Executive summary of an American Society for Radiation Oncology (ASTRO) evidence-based clinical practice guideline. Pract Radiat Oncol 2015;5:149-55.

9. Ramnath N, Dilling T, Harris L, et al. Treatment of stage III non-small cell lung cancer: Diagnosis and management of lung cancer, 3 rd ed: American college of chest physicians evidence-based clinical practice guidelines. Chest 2013;143:e314S-e340S.

10. Thomas DC, Arnold BN, Rosen JE, et al. The Significance of Upfront Knowledge of N2 Disease in Non-small Cell Lung Cancer. World J Surg 2018;42:161-71.

11. Bille A, Woo K, Ahmad U, et al. Incidence of occult $\mathrm{pN} 2$ disease following resection and mediastinal lymph node dissection in clinical stage I lung cancer patients. Eur J Cardiothoracic Surg 2017;51:674-9.

12. Obiols C, Call S, Rami-Porta R, et al. Survival of patients with unsuspected pN2 non-small cell lung cancer after an accurate preoperative mediastinal staging. Ann Thorac Surg 2014;97:957-64.

13. Yang CFJ, Kumar A, Gulack BCase is found: A National Cancer Data Base analysis. J Thorac Cardiovasc Surg 2016;151:1380-8.

14. Cerfolio R, Bryant A. Survival of Patients With Unsuspected N2 (Stage IIIA) Nonsmall-Cell Lung Cancer. Ann Thorac Surg 2008;86:362-6; discussion 366-7.

15. Tachi R, Hattori A, Matsunaga T, et al. The impact on the prognosis of unsuspected N2 disease in non-small-cell lung cancer: indications for thorough mediastinal staging in the modern era. Surg Today 2017;47:20-6.

16. Lee DH, Kim JB, Keum DY, et al. Long term survival of patients with unsuspected N2 disease in non-small cell lung cancer. Korean J Thorac Cardiovasc Surg 2013;46:49-55.

17. Sawabata N, Maeda H, Matsumura A, et al. Clinical implications of the margin cytology findings and margin/ tumor size ratio in patients who underwent pulmonary excision for peripheral non-small cell lung cancer. Surg Today 2012;42:238-44.

18. Wang EH, Corso CD, Rutter CE, et al. Postoperative radiation therapy is associated with improved overall survival in incompletely resected stage II and III nonsmall-cell lung cancer. J Clin Oncol 2015;33:2727-34.

19. Smeltzer MP, Lin CC, Kong FMS, et al. Survival Impact of Post-Operative Therapy Modalities According to Margin Status in Non-Small Cell Lung Cancer patients in the United States. J Thorac Cardiovasc Surg 2017;154:661-72.

20. Sun JM, Noh JM, Oh D, et al. Randomized Phase II Trial Comparing Chemoradiotherapy with Chemotherapy for Completely Resected Unsuspected N2-Positive Non-Small Cell Lung Cancer. J Thorac Oncol 2017;12:1806-13.

21. Drake JA, Portnoy DC, Tauer K, et al. Adding Radiotherapy to Adjuvant Chemotherapy Does Not Improve Survival of Patients With N2 Lung Cancer. Ann Thorac Surg 2018;106:959-65.

22. Francis S, Orton A, Stoddard G, et al. Sequencing of postoperative radiotherapy and chemotherapy for locally advanced or incompletely resected non-small-cell lung cancer. J Clin Oncol 2018;36:333-41.

23. Moreno AC, Haque W, Verma V, et al. Concurrent Versus Sequential Chemoradiation Therapy in Completely Resected Pathologic N2 Non-Small Cell Lung Cancer: Propensity-Matched Analysis of the National Cancer Data Base. Ann Surg Oncol 2018;25:1245-53.

24. Detterbeck F. What to do with "surprise" N2? Intraoperative management of patients with non-small cell lung cancer. J Thorac Oncol 2008;3:289-302.

25. Howington J, Blum M, Chang A, et al. Treatment of stage I and II non-small cell lung cancer: Diagnosis and management of lung cancer, 3rd ed: American college of chest physicians evidence-based clinical practice guidelines. Chest 2013;143:e278S-e313S.

26. Boffa DJ, Rosen JE, Mallin K, et al. Using the national cancer database for outcomes research a review. JAMA Oncol 2017;3:1722-8.

27. Cerfolio RJ, Bryant AS, Eloubeidi MA. Routine 
mediastinoscopy and esophageal ultrasound fine-needle aspiration in patients with non-small cell lung cancer who are clinically N2 negative: A prospective study. Chest 2006;130:1791-5.

28. Keller SM, Vangel MG, Wagner H, et al. Prolonged survival in patients with resected non-small cell lung

Cite this article as: Lieu DK, Ding L, David EA, Wightman SC, Atay SM, McFadden PM, Kim AW. Differential outcomes of residual disease in surgically-resected non-small cell lung cancer and the importance of guideline-concordant adjuvant therapy. J Thorac Dis 2021;13(5):2896-2909. doi: 10.21037/jtd-21110 cancer and single-level N2 disease. J Thorac Cardiovasc Surg 2004;128:130-7.

29. Ichinose $Y$, Kato H, Koike T, et al. Completely resected stage IIIA non-small cell lung cancer: The significance of primary tumor location and N2 station. J Thorac Cardiovasc Surg 2001;122:803-8. 